\title{
Considerações sobre trabalho e suicídio: um estudo de caso*
}

\author{
Considerations on work and suicide: a case study
}

\begin{abstract}
${ }^{1}$ Mestre em Administração. Universidade de Brasília, Brasília, Brasil.

2 Doutor em Administração, Professor do Programa de Pós-Graduação em Administração da Universidade de Brasília, Brasília, Brasil.

*Trabalho baseado em parte da dissertação de mestrado intitulada Patologia da solidão: o suicídio de bancários no contex to da nova organização do trabalho, apresentada ao Programa de Pós-Graduação em Administração da Universidade de Brasília em 2009.

Versão preliminar do trabalho apresentada no Encontro de Estudos Organizacionais (EnEO), organizado pela Associação Nacional de Pós-Graduação e Pesquisa em Administração (ANPAD), no período de 23 a 25 de maio de 2010 , em Florianópolis-SC.
\end{abstract}

A pesquisa foi realizada com recursos dos próprios pesquisadores.

Não há conflitos de interesses relacionados à elaboração do manuscrito.

Contato:

Marcelo Augusto Finazzi-Santos

SQS 409, bloco N, apto. 201, Brasília

$-\mathrm{DF}$

CEP: 70158-140

E-mail:

marcelofinazzi@hotmail.com

\section{Resumo}

As empresas vêm presenciando o suicídio de seus empregados, atribuído, de acordo com Dejours e Bègue (2010), às consequências negativas das novas organizações do trabalho. Com base no estudo de óbito de trabalhador bancário, o foco deste artigo é avaliar se o trabalho poderia ser um dos fatores relacionado à decisão de cometer-se o suicídio. Avaliou-se o significado qualitativo da morte sob o ponto de vista do irmão do suicida (ambos colegas de trabalho durante mais de 20 anos), entrevistado em 2009. Visto que esse tipo de análise produz volume significativo de dados sobre o fenômeno pesquisado, estes foram processados e analisados por meio de análise categorial. O bancário trabalhava na empresa havia três décadas e morreu em meados de 2000, faltando um ano para aposentadoria, após a esposa requerer o divórcio. $\mathrm{O}$ trabalho foi o contexto para compreender o processo que o conduziu à ruína familiar, à exasperação psíquica e, por fim, à morte. $\mathrm{O}$ caso não envolveu assédio moral, já que se tratava de empregado muito bem conceituado, mas de patologia associada à servidão voluntária, patologia essa cada vez mais estimulada como símbolo de sucesso. No ambiente de trabalho, problemas conjugais foram os fatores atribuídos como causa maior do suicídio, mais conveniente como forma de eximir responsabilidades perante o infortúnio, transferindo somente ao sujeito a culpa por conflitos pessoais ou desordens psíquicas.

Palavras-chave: suicídio; bancários; organização do trabalho; saúde do trabalhador.

\begin{abstract}
Companies have been facing suicide among their employees, which, according to Dejours and Bègue (2010), is a negative consequence of a new work organization. The focus of this study is to evaluate whether work was related to the decision of committing suicide, in a case of a bank employee. The qualitative significance of his death was evaluated from the point of view of his brother (both have been coworkers for over 20 years) who was interviewed in 2009. This analysis produced a great volume of data and information on the subject under study, and they were processed and analyzed by means of categorical analysis. The worker, who had been employed at a bank for three decades, committed suicide in 2004, just one year before his retirement and right after his wife had filed for divorce. Work was the context for understanding the process that led to the collapse of his family, to his psychological illness and, finally, to his suicide. This case did not involve bullying, since he was considered of good repute, but involved a pathology associated to voluntary servitude, which has been increasingly stimulated as symbol of success. At work, the primary cause of the suicide was attributed to marital problems, conveniently exempting responsibilities for the misfortune and blaming solely the subject for his personal conflicts or mental disorders.
\end{abstract}

Keywords: suicide; bank employee; work organization; occupational health. 


\section{Introdução}

As empresas vêm presenciando ocorrências de suicídios de seus empregados, levando-se à suspeita, de acordo com Dejours e Bègue (2010), da possibilidade de interrelação entre as mortes e as formas contemporâneas de organização do trabalho. Visto que a morte autoinfligida costuma atrelar-se, na maioria dos casos, à presença de desordens psíquicas (PRIETO; TAVARES, 2005), costuma ser difícil a avaliação de outros fatores que sejam anteriores à doença mental, tal qual aqueles relacionados ao contexto laboral, como elementos desencadeadores de alguns suicídios. Não é sem motivos que Dejours (2008) assevera que, em vista de condições psicopatológicas deterioradas, especialistas costumam concluir que ao fator trabalho se relega papel secundário para a consecução do óbito. De fato, Botega et al. (2006) esclarecem que caberia diagnóstico de transtorno psiquiátrico para aproximadamente 97\% das mortes intencionais, muito embora Gunnell e Lewis (2005) sejam precavidos ao alertar que doenças como depressão e esquizofrenia, por exemplo, relacionam-se, em muitas ocasiões, com comportamentos impulsivos em resposta às intempéries da vida. $\mathrm{O}$ desafio, por conseguinte, é extrapolar a compreensão de mortes violentas de trabalhadores, como homicídios e suicídios, para além da patologia individual, vislumbrando as patologias sociais que esses fenômenos são capazes de evidenciar.

Este estudo se orienta pela necessidade de instigar debate sobre a influência de adversidades relacionadas à organização do trabalho na decisão de alguém cometer o suicídio. Analisa-se, dessa forma, a morte de bancário após atear fogo ao próprio corpo, ocorrida na primeira metade dos anos 2000, sob o ponto de vista do irmão do falecido (ambos também foram colegas de trabalho), com objetivo de demonstrar elementos patológicos da administração contemporânea que tenham contribuído para o desfecho trágico. O setor bancário se mostra particularmente propício para o referido estudo de caso, haja vista a intensidade das reestruturações no segmento financeiro nacional (LARANJEIRA, 1997; SEGNINI, 1999), com forte impacto na subjetividade do trabalhador (MACIEL et al. 2006), tomando como referência o cenário de flexibilização do trabalho dos últimos anos (ANTUNES, 2000). De antemão, cumpre salientar que o suicídio é tema demasiadamente complexo para correlações lineares do tipo causa e efeito. $\mathrm{O}$ que se fará, portanto, é a análise de apenas um desses fatores, no caso, o trabalho, como interveniente para o óbito, cabendo alerta para a multiplicidade de situações relacionadas com o suicídio.

Pesquisa realizada por Maciel et al. (2006) concluiu que 4,37\% dos bancários estudados (população aproximada de 425.000 trabalhadores, em 2006) apresentavam quadro de ideação suicida, constatando, ainda, alta taxa de indivíduos com problemas de nervosismo, tensão e preocupação $(60,72 \%)$, transtornos de sono $(42,14 \%)$, dor crônica de cabeça $(37,37 \%)$, sensações desagradáveis no estômago (33,4\%), dentre outras. Quase 39\% dos entrevistados relataram vivências constrangedoras no trabalho relacionadas principalmente com a chefia (excesso de trabalho, autoritarismo e foco exagerado na produção). Xavier (1998) demonstra que, entre 1993 e 1995, 72 bancários brasileiros cometeram suicídio (um a cada 15 dias), número atualizado por Finazzi-Santos (2009): foram oficialmente mais 181 óbitos entre 1996 e 2005 (um a cada 20 dias), com a ressalva de que esse tipo de morte apresenta, de acordo com Schmidtke et al. (1999), elevado índice de subnotificação. Finazzi-Santos (2009) constatou ainda que quase $80 \%$ dos bancários suicidas eram homens, 60\% possuíam mais de 40 anos de idade e $52 \%$ eram casados. Além disso, as duas principais causas de afastamento de bancários para tratamento médico, de 1995 a 2008, tomando como referência o banco do estudo de caso, foram "doenças do tecido musculoesquelético e dos tecidos conectivos" (32\%) e "transtornos mentais e comportamentais" (23\%). Salientamos que a primeira causa também possui relação direta com a organização do trabalho em vista da elevada incidência de LER/DORT na categoria (ROSSI, 2008).

É bem provável que a maior parte dessas pessoas estivesse acometida de graves desordens psicológicas quando de suas mortes, o que não é suficiente, entretanto, para explicar parte das causas da patologia mental e o porquê de alguns terem elegido o trabalho como cenário para extinguir a vida. Suicídios no ambiente de trabalho não são mero detalhe, pois, como explica Dejours (2008), a pessoa dirige uma mensagem ao matar-se perante os colegas. Mais além, as pistas deixadas pelo falecido, como cartas, atitudes prévias, verbalizações, mudanças de comportamento, mesmo que o ato derradeiro se dê fora das paredes da empresa, são significativos para demonstrar parte das problemáticas subjacentes ao ato, evidenciando o papel de destaque, em certos casos, das condições deletérias do trabalho para o adoecimento físico e mental de trabalhadores.

Estudos sobre suicídio, via de regra, são predominantemente quantitativos e de caráter epidemiológico. Hjelmeland e Knizek (2010) demonstram que menos de $3 \%$ dos artigos publicados nos três principais periódicos em suicidologia (Archives of Suicide Research, The Journal of Crisis Intervention and Suicide Prevention e Suicide and Life-Threatening Behavior) utilizam abordagens qualitativas. Alvarez (1999) observa que o suicídio sempre foi visto com enorme desprezo e repulsa. Embora o ato ainda continue sendo chocante, a partir da publicação do excepcional livro de Emile Durkheim, O suicídio: estudo sociológico, o assunto passa a ser visto como tópico digno de pesquisa séria, desenvolvendo-se principalmente sob a ótica das ciências médicas. O efeito adverso, de acordo com Alvarez (1999), é que a preocupação em objetivar tem reduzido o máximo do sofrimento humano a estatísticas áridas: o que falta nas pesquisas, porém, é a racionalização filosófica completa e cabal do ato em 
si, ato esse intimamente relacionado à natureza humana, como demonstra Camus (2004). É por isso que na presente pesquisa houve aproximação epistemológica com a interpretação subjetiva (MORGAN, 1980), proposta que instiga o sujeito sob estudo a revelar suas características e natureza durante o processo de investigação.

Estudos gerenciais críticos ao mainstream funcional-positivista, de múltipas vertentes teóricas, fornecem importante quadro teórico de referência para compreender-se o contexto organizacional por trás da interface trabalho e suicídio, como, por exemplo, dominação e poder (FARIA, 2007), assédio moral (FREITAS; HELOANI; BARRETO, 2008), sofrimento psíquico (MOTTA; FREITAS, 2000), controle da subjetividade (BRITO et al., 2006) e manipulação ideológica (PAULA, 2002). Salienta-se que a sociologia clínica (PAGĖS et al., 1993; ENRIQUEZ, 1997a), a psicodinâmica do trabalho (LANCMAN; SZNELWAR, 2008), a ergonomia da atividade (FERREIRA, 2008), a saúde mental no trabalho (SELIGMANN-SILVA, 1994), apenas a título de limitado exemplo, evidenciam o caráter multidisciplinar de abordagens sobre a organização do trabalho e o sofrimento do trabalhador em suas inúmeras dinâmicas.

Embora seja vasta a literatura internacional sobre suicídio e trabalho - em contraste com as publicações nacionais -, tais estudos costumam desconsiderar as análises sociológicas das dinâmicas políticas intra ou extraorganizacionais porventura subjacentes à aludida relação, focalizando a correlação linear objetiva de suicídios por determinadas categorias de trabalhadores a partir de indicadores como idade, escolaridade, renda, estado civil, gênero, histórico de adoecimento mental, meio empregado para morte (KPOSOWA, 1999; GIBBS, 2000; STACK, 2001; WILHELM et al., 2004; MELTZER et al., 2008). Outros estudos correlacionam suicídio e contexto socioeconômico para determinar se crises econômicas ou desemprego poderiam aumentar a quantidade de suicídios (PRETI; MIOTTO, 1999; BLAKELY; COLLINGS; ATKINSON, 2003; TAYLOR, 2003; AGERBO et al., 2007). De forma geral, apontam-se como fatores de risco o estresse ocupacional, o acesso aos meios letais e o desemprego.

Por outro lado, estudos japoneses têm se mostrado particularmente importantes para a compreensão dos impactos dos novos métodos produtivos na subjetividade e na saúde do trabalhador. Nishiyama e Johnson (1997), Shields (1999), Nakao et al. (2007) e Hiyama e Yoshihara (2008) atribuem explicitamente as ocorrências de suicídios de trabalhadores ao excesso de estresse psicológico relacionado às penosas condições laborais, o que está se agravando em decorrência das rotinas de enxugamento de pessoal. O resultado são menos pessoas realizando mais tarefas para compensar a redução dos quadros (downsizing), com o consequente aumento da jornada de trabalho e a diminuição das horas livres. Alertam, inclusive, que dois fenômenos relacionados à organização do trabalho karoshi (morte por excesso de trabalho) e karojisatsu (suicídio por excesso de trabalho) - tornaram-se graves problemas de saúde pública, merecendo atuação incisiva das entidades governamentais e responsabilização judicial por parte das empresas envolvidas com os óbitos.

Há trabalhos de natureza prescritiva que abordam procedimentos para minimizar a possibilidade de suicídios nas empresas. Embora seja relevante fornecer subsídios práticos para que administradores atuem no sentido de evitar tragédias, cabe salientar que essas abordagens ignoram peremptoriamente qualquer tipo de análise dos fundamentos sociais negativos que estão na origem da indução ao suicídio. Ou seja, fornecem meios paliativos para administrar as consequências inerentes à precarização do trabalho basicamente por meio do gerenciamento do estresse, além de deslocar o foco dos problemas estruturais intrínsecos aos métodos produtivos para o sujeito (culpabilização do trabalhador). Exemplo disso é a recomendação de Bedeian (1982) que, a partir de referências publicadas sobre ocupação e suicídio, assevera a necessidade de aprimorarem-se os métodos de seleção de pessoal, nos casos de profissões com elevadas incidências de suicídio, buscando-se sujeitos com forte estabilidade emocional para suportar as asperezas do labor diário.

De qualquer forma, Bedeian (1982) sugere medidas interessantes, como capacitar os empregados para que reconheçam sinais de depressão e aceitem as próprias limitações, além de ressaltar que programas organizacionais preventivos em saúde mental, com protocolos definidos para atuação durante crises, são importantes para que as pessoas se sintam encorajadas a buscar ajuda em caso de dificuldades emocionais. Goldman e Schmalz (2003) alertam sobre o auxílio a ser prestado aos empregados com ideações suicidas, reforçando a empatia necessária ao ouvinte em compreender a dor alheia (sem, entretanto, invadir a privacidade do confidente), para, em seguida, oferecer a esperança de que soluções para os problemas podem ser encontradas. Caso as dificuldades façam alusão ao trabalho, as autoras aconselham que se tomem iniciativas concretas para solucioná-las, reforçando que sinais de desequilíbrio mental ou desesperança demandam encaminhamento ao serviço médico.

E quando o colega comete o suicídio? A partir da morte inesperada de uma enfermeira, Clements et al. (2003) sugerem reuniões comunitárias entre os companheiros de trabalho, conduzidas por profissionais habilitados, com objetivo de promover plataforma para superação dos pensamentos e sentimentos resultantes do episódio traumático. Os autores orientam abordar tópicos que encorajem as pessoas a reconhecerem que a dor sentida é real, na medida em que se lamenta a perda de alguém tão próximo, dor essa que costuma manifestar-se de diversas maneiras (física, emocional e espiritualmente). Recomenda-se, por oportuno, estimulo às pessoas para lutar contra o estado de solidão, evitar se culparem pelo ocorrido e procurar auxílio especializado, caso haja dúvidas com o próprio bem-estar e segurança.

Em muitos casos, suicídios são evitáveis: dificuldades para perpetrar o plano de morte costumam contri- 
buir significativamente para demover o potencial suicida de seu intento. O que se tem feito, todavia, quando o colega denota conduta anormal sem razão aparente? Berman (1993) descreve o caso de uma trabalhadora cujo rendimento profissional começa cair bruscamente, em curto tempo, somando-se a estranhas mudanças de comportamento, incompatíveis com o seu habitual modo de ser. Ao constatar que a moça passava por sérias dificuldades, seja de ordem pessoal ou profissional, a empresa poderia ter adotado postura mais ativa, demonstrando solidariedade e encaminhando-a para avaliação médica. O fato é que os colegas de trabalho e os superiores passaram a ignorá-la, cogitando, inclusive, a sua demissão: o desfecho foi a morte após precipitação do prédio em que morava.

Na verdade, não são apenas as empresas que estão despreparadas para lidar de forma respeitosa e humana com potenciais suicidas. Sampaio e Boemer (2000), apoiados em suas experiências no mundo hospitalar e no Centro de Valorização da Vida, concluíram que os profissionais da saúde têm demonstrado despreparo no auxílio aos sobreviventes de suicídios, demonstrando desprezo, agressividade e preconceito.

Dejours e Bègue (2010, p. 47) são enfáticos ao atribuir a multiplicação de suicídios não apenas à injustiça ou ao assédio moral nos ambientes corporativos, mas, sobretudo, ao silêncio daqueles que se calam frente ao sofrimento alheio:

Ser traído pelos colegas, pelos próximos, é mais doloroso do que o próprio assédio moral. Assediada, mas se beneficiando do apoio moral e da atenção dos outros, a vítima resiste muito mais psiquicamente.

Esses autores consideram três fatores no cerne da desagregação do mundo social do trabalho e do rompimento dos laços de solidariedade, que são os programas de qualidade total, a avaliação individualizada dos desempenhos e o privilégio do "gerencialismo" (ênfase nos números e na objetividade) sobre os valores do trabalho (ênfase na qualidade e na cooperação). A exacerbação do individualismo decorre do conjunto de mudanças estruturais nos sistemas econômicos e produtivos a partir da década de 1970, conduzindo à difusão do toyotismo como paradigma preponderante para a expansão do capitalismo industrial e financeiro (LIPIETZ, 1991; DRUCK, 1999).

É provável que Xavier (1998) seja o primeiro autor nacional a realizar um estudo completo sobre o suicídio exclusivamente a partir do enfoque do trabalho ao avaliar mortes ocorridas em instituições financeiras durante a primeira metade da década de 1990. A tese do autor é que a pressão por resultados e o autoritarismo como instrumento gerencial acirram os conflitos de poder e estão na origem da depressão entre bancários. Os medos (assalto, adoecimento, demissão), a servidão voluntária (traduzida sob o conceito de “empregabilidade”), o enfraquecimento dos sindicatos, a pressão para o cumprimento de metas desafiadoras e, por fim, as ameaças sem limite compõem cenário em que a nulidade de si mesmo emerge como síndrome dos tempos contempo- râneos. Não é sem motivos que as pessoas optam por se matar, em certas ocasiões, exatamente no mesmo ambiente em que vislumbravam construir uma vida feliz.

Bilhete deixado por um bancário que se enforcou com a gravata no banheiro do local de trabalho, de acordo com relato de Benevides (2002, p. 89), é bastante ilustrativo:

\begin{abstract}
Não agüento mais trabalhar no Banco. É muita pressão. Sempre procurei fazer as coisas mais certas possíveis mas o Banco mudou e sinto-me desamparado. Não existe qualquer falcatrua e nunca roubei nada do Banco. Apenas o fardo está muito pesado para mim. No ano passado fiz tratamento psiquiátrico e não melhorei. Espero que minha família entenda que eu escolhi esta atitude e me perdoe. Estou doente. Não sei viver assim. Perdão.
\end{abstract}

Jinkings (2002) igualmente avalia o cotidiano do bancário permeado de insegurança, estresse e medo, principalmente após o aprofundamento dos processos de reestruturação produtiva que instauraram tensão nos diversos setores. São relatados casos de distúrbios osteomusculares, estresse, depressão, angústia, tensão, alcoolismo, como resultado de jornadas longas, extenuantes e ritmos de trabalho intensos. Programas de nítida inspiração toyotista, como aqueles que preconizam a qualidade total e a remuneração variável, instigam a máxima produtividade e exacerbam o individualismo, aprofundando os mecanismos de controle da subjetividade e o poder das organizações sobre o sujeito, convertendo a gestão do medo em gestão do afetivo - o que se vende é a imagem da empresa "democrática" e "participativa”. Rodrigues (2004), de forma semelhante, faz relato contundente da dramática condução de projeto de ruptura cultural instituído em um banco público cuja marca seria o programa de desligamento em massa como representação ritualística do rompimento com o passado e do prenúncio de novas relações de trabalho, mesmo que ao custo do terror permanente.

Feitas essas considerações teóricas, passemos à investigação do suicídio.

\section{Percurso metodológico}

No presente estudo, o foco é o significado qualitativo do suicídio de um trabalhador bancário, visto que esse tipo de análise produz grande volume de dados e informações sobre o fenômeno pesquisado, permitindo-se compreender a subjetividade inerente aos sujeitos e ao contexto em que ocorreram os fatos. Conforme ressaltam Strauss e Corbin (2008, p. 24), a pesquisa qualitativa procura: “[...] obter detalhes intrincados sobre fenômenos como sentimentos, processos de pensamento e emoções que são difíceis de extrair ou de descobrir por meio de métodos de pesquisa mais convencionais", mostrando-se, portanto, perfeitamente adequado às características desta pesquisa.

Trabalhar com suicídios requer esforços adicionais do pesquisador por meio de investigações que normal- 
mente se baseiam em autopsias psicológicas para perscrutar a intimidade do falecido (HAWTON et al., 1998). Trata-se de método indireto, baseado em entrevistas com informantes próximos à vítima, auxiliando na reconstituição dos acontecimentos que desembocaram no óbito. Salienta-se, entretanto, que não foram utilizados instrumentos clínicos típicos de tal técnica nesta pesquisa visto que a finalidade foi avaliar a evolução dos fatos sob a ótica de testemunha privilegiada, articulando esses fatos com interpretações ativas e inclusão do ponto de vista dos pesquisadores.

Significa, portanto, que não houve o tradicional afastamento sujeito-objeto, típico dos métodos nomotéticos e das autópsias psicológicas, pois se buscou não apenas observar distanciadamente o fenômeno, mas compreender e atribuir significado às declarações do entrevistado, aproximando-se da fenomenologia hermenêutica heiddegeriana (RAY, 1994; HEIDEGGER, 2005). Nessa vertente, as realidades se constituem a partir das experiências pessoais e da visão de mundo do indivíduo, de modo que as premissas e as percepções dos pesquisadores estiveram presentes em todo o estudo, da seleção do tema, passando pela escolha do referencial teórico, até as análises e as considerações quanto às categorias propostas pelos juízes. As múltiplas abordagens fenomenológicas têm se mostrado promissora alternativa metodológica para pesquisas em ciências sociais aplicadas, como demonstram Paiva Júnior e Mello (2008).

Neste artigo, os nomes das pessoas, do banco e dos setores citados são fictícios para assegurar o anonimato dos participantes e da empresa.

Este estudo foi realizado a partir do ponto de vista de uma testemunha privilegiada do processo que culminou na morte do bancário. Escolheu-se o caso do suicídio de Carlos*, dentre outros que os pesquisadores tiveram acesso, pois a testemunha, além da relação de parentesco (irmão), também fora colega de trabalho do falecido por duas décadas (compartilhavam o setor), circunstâncias que lhe conferiam visão apurada sob os contextos pessoal e profissional resultantes na morte. Apesar de o estudo centrar a história do bancário falecido, as consequências do episódio na vida do entrevistado também foram avaliadas, visto que forneceram dados importantes para a compreensão das relações de trabalho.

Trata-se, portanto, de estudo de caso, método apropriado para pesquisas em que há pouco conhecimento acumulado e sistematizado. Cabe ressaltar que a abordagem qualitativa se ocupa de detalhes sobre processos complexos, como experiências pessoais, comportamentos, emoções, sentimentos, movimentos sociais, práticas organizacionais, fenômenos culturais, ou seja, a subjetividade que é própria do ser humano e que os métodos convencionais não captam com tanta acuidade (STRAUSS; CORBIN, 2008). Dessa forma, a preo- cupação é com o volume significativo de informações que alguns poucos sujeitos são capazes de representar sobre o fenômeno em estudo, sendo razoável, dessa forma, o uso de amostra não probabilística intencional (GASKELL, 2002).

O episódio, ocorrido em uma grande cidade em meados de 2000, foi descoberto após breve relato de delegado sindical. Em seguida, manteve-se contato telefônico com o irmão da vítima, convidando-o a participar de entrevista sobre a vida e o trabalho do suicida, bem como suas impressões pessoais sobre os motivos do óbito. Ambos trabalhavam no Banco "X" * . Em vista dos sentimentos que poderiam ser suscitados durante o encontro, principalmente em função das vivências negativas, a entrevista foi realizada em local previamente agendado, em fevereiro de 2009, escolhido pelo irmão do falecido, como forma de deixá-lo à vontade para relatar suas experiências. Antes da entrevista, forneceu-se ao entrevistado oportunidade de obter todos os esclarecimentos que julgasse necessários sobre o estudo. Assim, a entrevista foi realizada com Gustavo*, irmão de Carlos (o bancário suicida).

A entrevista foi gravada e transcrita na íntegra, mediante consentimento formal de Gustavo, com duração de duas horas. O roteiro semiestruturado da entrevista seguiu proposta de Mendes (2007), priorizando a investigação de quatro temas: (a) contexto do trabalho; (b) sentimentos no trabalho; (c) estratégias de enfrentamento da organização do trabalho; (d) patologias sociais decorrentes da organização do trabalho. Apenas pequenas inserções foram realizadas durante o encontro, visto que se pretendeu deixar que o entrevistado transcorresse livremente sobre os temas propostos. Esse procedimento objetivou não direcionar as suas respostas - principalmente quanto à possível vinculação entre o trabalho e o suicídio - para que os sentimentos relatados fossem os mais fidedignos possíveis.

O tratamento dos dados foi realizado por meio da análise do núcleo de sentidos proposta por Mendes (2007), técnica derivada da análise de conteúdo de Bardin (1977). O método se baseia na inferência interpretativa, induzindo o pesquisador a desvendar o escondido, o não dito, os significados implícitos das mensagens cujo conjunto de documentos submetidos aos procedimentos analíticos (corpus) deve ser avaliado à luz das regras de exaustividade, representatividade, homogeneidade e pertinência. Procura-se agrupar o conteúdo manifesto e oculto a partir da repetição de certos temas presentes na entrevista, permitindo a criação dos núcleos do sentido.

Dois juízes - psicólogo e administrador -, habituados com a técnica criaram as categorias que foram descritas na seção "Revelações do campo". Para tanto, o caminho percorrido foi: (a) leitura da entrevista; (b) marcação das verbalizações que se destacavam; (c) re-

\footnotetext{
* Nome fictício.
} 
petição de tais verbalizações; (d) delimitação de fenômenos para um tema em comum, ou seja, assuntos que surgiam com base no conjunto de verbalizações com significados similares; (e) criação das categorias a partir do conjunto de fenômenos coerentemente articulados.

O procedimento se mostrou apropriado para o tratamento dos dados obtidos na pesquisa de campo, visto que se trabalhou com entrevista que revelava o sofrimento subjetivo por meio de verbalizações impregnadas de significados psicológicos latentes e manifestos, sobretudo contraditórios e repletos de mediações. Os resultados apontados pelos juízes puderam ser analisados, na sequência, pelos pesquisadores. Trata-se, portanto, de duplo processo hermenêutico em que os juízes e os pesquisadores interpretam a análise (versão) que apresenta Gustavo sobre a morte do próprio irmão.

Salienta-se que o projeto contendo a pesquisa integral, incluindo a fase descrita neste artigo, foi previamente submetido ao Comitê de Ética vinculado ao Instituto de Ciências Humanas da universidade de realização da pesquisa, recebendo parecer favorável.

\section{Revelações do campo}

Carlos ingressara no Banco "X" com menos de 20 anos de idade, em meados da década de 1970. Quando da morte, possuía formação em ciências exatas, com especializações na área. Ocupava cargo técnico de relevância. No local trabalhavam centenas de empregados, muitos dos quais treinados por ele, visto que também atuava como tutor dos novatos. Sob sua responsabilidade estavam projetos estratégicos, de forma que sua experiência lhe conferia prestígio e contato direto com a cúpula da empresa, além de acesso a informações a partir de sua própria residência, prerrogativa conferida a poucos, possibilitando-o trabalhar ilimitadamente nas importantes missões que lhe eram confiadas.

\section{Categoria-síntese 1 - Trabalho versus família: confli- tos à vista}

Verbalização representativa:

Se você falar pra ele: 'estou te pedindo isso hoje. Eu preciso desse resultado amanhã de manhã...'. Ele virava a noite. Era tanto, que ele tinha acesso da casa dele. Ele ia pra casa dele e, da casa dele, ele trabalhava. Ele virava a noite trabalhando. Trabalhou... muitas vezes, muitas noites. Ele não trabalhava 8 horas. Ele trabalhava 24 horas. Não só vestia a camisa, não: vestia o 'macacão'. Era um profissional excelente.

O filho dele [de Carlos] tem uma mágoa de que em algumas ocasiões o pai deixou de estar presente... ele levou a família para um balneário... por várias vezes levou a família pra lá e voltou para trabalhar em férias. Em férias. Não foi uma nem duas vezes, não.

A dedicação integral ao trabalho é a marca preponderante de Carlos. Para tanto, cada projeto é encarado com seriedade máxima, de tal forma que as suas ener- gias são centralizadas em vista dos resultados esperados. Dessa forma, a jornada de trabalho se estende muito além do horário previsto, incluindo os fins de semana e - comumente - as férias. Tal dedicação vem dos tempos do colegial, quando já se centrava nos desafios escolares com garra e persistência meticulosa. Sozinho, é capaz de executar tarefas normalmente delegadas a vários empregados, tamanha é a capacidade de concentração empenhada em seus afazeres. As relações familiares, entretanto, gradativamente se deterioram à medida que as exigências profissionais consomem o escasso tempo disponível para convívio com os entes próximos. Carlos nutre verdadeiro sentimento de amor pela família, é bem verdade. Orgulha-se dos filhos, estudiosos e afetos às ciências exatas, como ele. Pretende continuar com o casamento, tentar uma reconciliação com a esposa, corrigir as longas ausências daqueles últimos tempos.

\section{Categoria-síntese 2 - Separação conjugal e insensibili- dade da chefia: prenúncios de uma tragédia}

\section{Verbalização representativa:}

\begin{abstract}
Só que você tem que levar em consideração o mês que ele começou a buscar locais pra trabalhar no mesmo setor e, cada vez que ele encontrava um lugar pra trabalhar, o chefe dele dizia que não liberava. E isso foi por várias vezes. Eu diria que pela competência dele... aí, o que faziam? Não deixavam ele sair. Em apenas três meses, se não me engano, foram cinco vezes. Cinco negativas [para mudança de setor]. Na última vez ele saiu do local de trabalho e foi até à sala do superior. Lá tiveram uma discussão - e foi uma discussão bem pesada. Os dois gritaram, gritaram muito. Só não se bateram.
\end{abstract}

Carlos tenta manter o casamento. Sugere a terapia de casal, planeja a aposentadoria para o ano seguinte. Seria a oportunidade de centrar-se na família e recuperar o tempo perdido. As noites, os fins de semana e as férias não seriam mais dedicados aos sucessivos projetos da empresa. Poderia continuar trabalhando, contratado como prestador de serviços. Nada, porém, que lhe exigisse o mesmo ritmo frenético de antes. Poderia dosar melhor o tempo. Mas não há mais tempo: a esposa se decide pelo divórcio. Os sentimentos saudosos derivados da recente perda afetiva, contudo, conduzem-no à tentativa de assegurar que a separação seja definitiva, inclusive de "corpos”. A separação está sendo bastante dolorosa. Por questóes relacionadas à reorganização interna de setores, Carlos é obrigado a conviver com a ex-esposa, por conta da proximidade dos locais de seus empregos. Para tanto, requisita a permanência no prédio antigo, em outro cargo. A competência profissional lhe abre as portas e as oportunidades surgem naturalmente. São muitos convites para remoção. Poderia escolher o local, pois as vagas estão disponíveis. A dedicação irrestrita ao trabalho, entretanto, é utilizada como justificativa para ter sucessivas propostas negadas. Carlos se desespera. Dedicara-se exaustivamente à organização durante quase 30 anos. 
Naquele momento difícil, sente-se desamparado. Trava severa discussão com os superiores, exige satisfações: seria o momento de requerer a contrapartida pela subordinação que lhe custava a família. Seus apelos são ignorados, determinando-se que acompanhe o restante da equipe na mudança de prédio. É possível que, pela primeira vez, Carlos se revolte contra uma ordem recebida a ponto de negar seu cumprimento e bater de frente com os mandatários. A mente aturdida parte para o confronto. Perdeu a família. Qual seria, então, o sentido do trabalho, daquela dedicação ilimitada? Com a separação consumada, seria tudo ou nada: remoção de setor ou demissão. O desespero, porém, atinge proporções inimagináveis.

\section{Categoria-síntese 3 - Suicídio}

\section{Verbalização representativa:}

Ele queria pedir demissão do banco e, naquele momento, ia pedir demissão do banco e estava faltando pouco para ele completar 30 anos de serviço. Ele só me falou assim: 'Acabou! Eu vou pedir demissão do banco amanhã'. Só falou isso pra mim. Eu falei: ‘Que é isso, rapaz? Nós já conversamos, você estava mais tranquilo'. E ele disse: 'Acabou, eu não trabalho no banco um dia sequer.' Volto a dizer: foi exatamente... ele faleceu exatamente no dia em que completou 29 anos de banco. Então, ele morreu no dia em que completou 29 anos de banco. Segundo consta no inquérito policial, ele comprou gasolina no posto de combustível e jogou a gasolina no corpo. Eu sei o seguinte: ele teria jogado gasolina no corpo... e ateou fogo.

E... quem encontrou ele [Carlos] foi um carro que ia passando, que viu aquela cena de ele correndo com fogo de um lado para outro, correndo em círculos, nessa corrida ele tropeçou e caiu. A pessoa tentou apagar o fogo com o extintor de incêndio. Como não foi suficiente pra apagar, ele pegou a jaqueta e cobriu o corpo. Ele teria dito à pessoa que o socorreu, que perguntou quem foi que fez aquilo com ele, e ele teria dito que foi ele mesmo. E, ai, a pessoa, não satisfeita, ainda perguntou, pra saber... de repente, ele estava delirando. Indagou de novo e ele teria respondido, pela segunda vez, que foi ele mesmo, a pessoa perguntou o porquê e ele disse: 'porque eu quis'.

Carlos decide que não trabalharia na empresa um dia sequer. Falta-lhe meses para a aposentadoria proporcional, mas a situação se torna insustentável. O fato é revelado ao seu irmão, adquirindo importante significado: a vontade de abandonar o emprego evidencia o vínculo entre o trabalho e os dramas familiares, os quais estiveram intimamente relacionados ao longo dos anos. O segundo aparece como resultado direto do primeiro. Não é à toa que, consumada a separação conjugal, o bancário se indigna com a empresa, já que toma consciência da relação subserviente de anos a fio e, em seguida, por razões práticas, quando tem negado os pedidos para remoção. Por isso a decisão radical: demissão, apesar de faltar tão pouco para a aposentadoria. Apesar da costumeira estabilidade psicológica, sente-se fragilizado. Precisava apenas de um pouco de empatia naquele momento. Não obteve. Os ânimos exaltados da discussão áspera que manteve com os superiores, na parte da manhã, contribuíram para que, no início da noite, também brigasse com a família, comportando-se de modo agressivo. Carlos está transtornado, fora de si, irreconhecível. Profissão e família: seria possível separá-las? É provável que Carlos tenha descoberto que os fios condutores de uma e outra estavam irremediavelmente entrelaçados. Às 19 horas Carlos liga para Gustavo e comunica que pediria demissão no dia seguinte. Desliga o telefone, tornando-se incomunicável, e parte para seu destino. Poucas horas mais tarde, encharca-se com gasolina, em avenida próxima à residência, e ateia o fogo. Esse comportamento se relaciona com formas extremas de punição e protesto, símbolo da dor máxima que o corpo pode sentir. Não há como permanecer inerte perante a imagem de uma pira humana. O sentimento de aflição é inevitável. A autoimolação exterioriza, por meio da violência brutal contra o próprio corpo, uma dor imperceptível, mas que arde por dentro com muito mais intensidade do que as labaredas visíveis. Morre horas depois, com queimaduras de terceiro grau em quase todo o corpo. Foi a sua forma de protesto e, por que não dizer, de autopunição. As pessoas desejam amenizar as dores da morte. Carlos, por sua vez, prefere padecer na carne o suplício das chamas.

\section{Categoria 4 - Dor e silêncio: ensurdecedor silêncio}

\section{Verbalização representativa:}

É o que falei pra você: houve uma reunião [da cúpula], que era a orientação do Banco sobre o procedimento de todo mundo lá no setor. Ninguém me perguntava o que foi que aconteceu. Assim, uma coisa normal... sabe... aconteceu um acidente... 'Mas, como é que foi? O que aconteceu?' Ninguém me perguntou nada. Era como se nada tivesse acontecido no mundo. Aquelas pessoas mais próximas me desejaram os pêsames e só. Ninguém me perguntou o porquê. Bom, é... não me entregavam mais nenhum serviço... os serviços eram entregues a outros colegas do setor. Eu batia o cartão e ficava ali. Depois, passado um mês, um colega veio falar comigo: 'Mas, como é que você consegue ficar aí se ninguém fala contigo?'

Horas depois do óbito, os executivos se reúnem para tratar do ocorrido. A pauta da reunião, porém, é mantida em segredo, mas o conteúdo chega ao conhecimento de Gustavo por meio de canais informais. No trabalho não se toca no assunto. Ninguém da ativa comparece ao velório, apenas aposentados. Os colegas de setor e os chefes igualmente ignoram o óbito, estabelecendo-se pacto de silêncio e cumplicidade para que ninguém se comprometa. As pessoas passam a negar, inclusive, que a acalorada discussão entre Carlos e os superiores tenha ocorrido. Os demais setores da empresa, incluindo o departamento de recursos humanos, também ignoram os acontecimentos, da mesma forma que as entidades sindicais e a imprensa. A polícia é pressionada a concluir as investigações com a maior brevidade possível. Ninguém ousa questionar Gustavo sobre os motivos daquele ato tão extremo, visto que o medo e a possibilidade de retaliações, no trabalho, são reais. Gustavo é isolado, não recebe tarefas, talvez pelo fato de agir no sentido de que o inquérito policial não seja concluído sem que ao menos 
os administradores do banco sejam ouvidos. O serviço médico da empresa o encaminha friamente para o setor de assistência mental, sem que a médica lhe dê qualquer explicação ou lhe dirija o olhar. Gustavo se descreve como uma "peça substituível”, relegado ao esquecimento, da mesma forma que a memória do irmão.

\section{Análises e considerações}

O destaque no caso é a relação dúbia entre a família e o trabalho. Pelo fato de ter assumido as responsabilidades profissionais como prioridade, os conflitos familiares se acentuam ao longo dos anos. Carlos acreditava nos valores do Banco "X", internalizando-os como pilares de sua vida. Portanto, não questionava o fato de trabalhar além do expediente, abdicar dos fins de semana ou das férias, evidenciando o indivíduo ideologicamente subjugado e dependente da empresa para ser feliz (TRAGTENBERG, 1985; FREITAS, 1999). Ingressara na empresa em uma época, na década de 1970, em que as relações de trabalho eram tipicamente paternalistas. Pelo menos foi essa a imagem disseminada no setor bancário antes das reestruturações que resultaram na intensificação do trabalho e na instabilidade dos empregos. De qualquer forma, Carlos era remanescente de uma geração subjetivamente doutrinada para nutrir relação afetiva com o trabalho (ENRIQUEZ, 1997a).

A família girava em torno dele, que, por sua vez, administrava a vida em decorrência das obrigações profissionais. A sua dedicação era motivo de segurança e tranquilidade para os superiores, os quais nele depositavam confiança irrestrita. A introspecção dos valores presentes no discurso oficial da empresa estava fortemente arraigada em seu caráter, induzindo-o à adesão irrestrita ao projeto organizacional (SIQUEIRA, 2006). Enquanto os demais empregados ajustavam a tarefa à jornada de trabalho, Carlos ajustava a jornada de trabalho à tarefa, mesmo que, para tanto, fosse preciso valer-se das horas de repouso, dos fins de semana ou das férias. Essa obstinação lhe conferiu condição diferenciada em relação aos demais, sendo-lhe designados apenas os projetos de suma importância. A total mobilização subjetiva do bancário, por parte da organização do trabalho, exacerbava o espírito individualista, conduzindo-o a dedicar-se com maior afinco às suas atividades e, por conseguinte, ao plano de lucratividade da empresa (GRISCI; BESSI, 2004).

Carlos nem sempre estava em casa para dedicar a mesma atenção à esposa e aos filhos e, mesmo quando estava no lar, comumente se envolvia com tarefas pendentes de finalização. Com o tempo, o desgaste desse modo de vida pode ter tornado a relação com a esposa insustentável, favorecendo comportamentos indesejados de raiva, hostilidade e relacionamento interpessoal insatisfatório, típicos de sujeitos workaholics (MOTA; TANURE; NETO, 2008). O processo é bastante traumático. Os anos de dedicação incondicionais detonam processo de raiva contra si mesmo pelo fato de não ter sido capaz de dosar adequadamente as obrigações pro- fissionais e familiares. Igualmente se exaspera contra a devoção irrestrita ao trabalho, causa típica de sofrimento psíquico em profissionais atribulados com rotinas estafantes (ALMEIDA; MERLO, 2008).

O excelente histórico profissional lhe abriu muitas portas para remoção, as quais foram fechadas pelos superiores sob a justificativa de que sua competência era indispensável ao bom funcionamento do setor. Assim, apesar do discurso amplamente veiculado de responsabilidade social e respeito aos "colaboradores", as negativas de transferência demonstraram que o seu valor era mensurado em função da resiliência em amainar seus problemas familiares em prol dos interesses instrumentais da empresa (LEITÃO; FORTUNATO; FREITAS, 2006), evidenciando a distância entre o discurso bem-intencionado e as práticas organizacionais subordinadas às considerações estritamente pragmáticas (SARAIVA; IRIGARAY, 2009).

Carlos, sozinho, desempenhava múltiplas tarefas, que - em situação normal - seriam realizadas por uma equipe. Sua rigidez moral em cumprir as obrigações com qualidade, por razão óbvia, escasseava o tempo livre. Dejours (2003) assegura que os empregados, nas novas organizações do trabalho, são compelidos a decisões perversas: trabalhar mal para dar conta de todas as tarefas, à custa de prejuízo ao senso de responsabilidade moral, ou trabalhar bem, à custa de graves prejuízos à saúde física e mental. Conforme os problemas familiares se intensificavam, reavaliava os valores pessoais e a carreira, dando-se conta de que se comportara como um funcionário excepcional, mas à custa da felicidade. É bastante revelador, dessa forma, que ele tenha decidido demitir-se da empresa ao ter os requerimentos negados. Não seria razoável esperar que alguém, a poucos meses da aposentadoria, abandonasse o emprego. Carlos se destacava pelo espírito prático e racional de suas decisões, típico de pessoas afetas à exatidão dos números. Seu raciocínio era lógico e coerentemente linear, conforme assevera Gustavo. Para que, então, desligar-se tão abruptamente daquele emprego estável, que lhe proporcionava inúmeros benefícios sociais e um salário suficiente para manter um padrão de vida confortável? Provavelmente tenha percebido que se tratava de mero objeto manipulável, literalmente um "recurso" humano, fenômeno típico da supremacia da racionalidade instrumental na gestão contemporânea (GUERREIRO RAMOS, 1981; ENRIQUEZ, 1997b).

O bancário incorporou como seu o imaginário difundido pela empresa, transformando-a em objeto de amor e identificação (PAGÈS et al., 1993). Por isso a decisão radical: pedir demissão. $\mathrm{O}$ casamento com a esposa estava desfeito. O casamento com a empresa também estava desfeito. Arruinaram-se ao mesmo tempo. Do modo mais doloroso, percebeu que, no embate com a organização, a correlação de forças é desproporcional. $\mathrm{O}$ amor devotado à empresa não era correspondido com a mesma intensidade: o controle ideológico e as estruturas psíquicas de dominação resultaram em quadro de servidão voluntária (CALGARO; 
SIQUEIRA, 2008). Sacrificou-se, renunciou em nome da glória e do triunfo, traduzidos não apenas em um cargo de responsabilidade, mas, principalmente, no regozijo decorrente do ilusório reconhecimento daqueles que o rodeavam. Carlos não costumava transgredir, enquadrando-se costumeiramente às regras, observa Gustavo. Participava prazerosamente do jogo da empresa, fazendo parte do clube de raros. Por isso buscava ser o melhor, renunciando a si mesmo na tentativa de superar-se: a motivação não era o trabalho, em si, mas a obrigação de ser e agir como vencedor (FREITAS, 1997; HELOANI, 2003). Carlos personificava o indivíduo útil, dócil e disciplinado ao trabalho (FOUCAULT, 1987), tão caro às organizações.

Carlos tinha em Gustavo o irmão e amigo, mas, mesmo para este, não confidenciou qualquer ideação mórbida. Conversavam sobre a morte, mas em outro contexto. Carlos manifestara que, quando morresse, pretendia ser cremado para não importunar as pessoas com os trâmites do enterro. Talvez nesse ponto resida parte da explicação para ter optado pela imolação por fogo. Não é fácil conceber esse tipo de morte, método dolorosamente lento e cruel de extinguir a vida (PAIVA, 2006). De qualquer forma, a conjugação de dois fatores, no mesmo dia, parece ter sido crucial para impulsioná-lo ao óbito: as agressivas discussões com os superiores e com os familiares.

Consideramos provável que a decisão de cometer o suicídio se alimentava em seu íntimo, tornando-o apto a executar algum plano oculto em decorrência dos acontecimentos vindouros. Quando o sofrimento mostra a sua face mais escura, não há hesitação. A data do suicídio e a decisão de desligar-se da empresa podem ser interpretados como indícios da forte mobilização do trabalho na psique do falecido, tratando-se de significativas mensagens quanto ao doloroso sofrimento afetivo que se encontrava, originados do sentimento de solidão perante a comunidade do trabalho (DEJOURS, 2008).

No dia seguinte, quando agonizava as últimas horas de sua vida, o alto escalão do banco se reuniria para as primeiras tratativas quanto ao assunto. Silêncio mórbido toma conta do setor, relata Gustavo. Os empregados têm medo de externar qualquer tipo de reação, apesar de tratar-se de colega muito conhecido. Havia uma espécie de acordo para blindar aqueles que dificultaram as remoções de Carlos, de forma a transferir o foco para a separação conjugal, recaindo toda a responsabilidade unicamente sob o sujeito como forma de eximir a empresa de responsabilidades quanto à produção do sofrimento (FLACH et al., 2009). Não se divulga, porém, a possível causa do drama conjugal: o excesso de trabalho, que prejudicava o convívio familiar. Sobre esse ponto, é revelador o depoimento acerca das frequentes viagens de férias familiares interrompidas pela metade com o retorno antecipado de Carlos após convocação para resolver questões de trabalho.

Gustavo passa a ser isolado no setor após a morte de Carlos. Não mais recebe qualquer tarefa, talvez como re- taliação por dificultar o rápido desfecho do inquérito policial, como queria o banco para abafar qualquer prejuízo à imagem corporativa. Ninguém comentava o assunto em decorrência do medo de represálias: Carlos deixou de "existir", apesar de 30 anos no setor. Quando alguém morre, são normais as manifestações de pêsames, ainda mais quando o falecido era respeitado e admirado. Gustavo, por sua vez, recebe alguns poucos - e contidos sinais de solidariedade. Nada mais do que isso. O entrevistado é enfático ao ressaltar que a empresa interviera, por meio de sua influência, para que o ocorrido caísse no esquecimento. Foi preciso buscar realocação em outro núcleo, desempenhar outra tarefa. Gustavo, a partir de então, atenta contra os interesses organizacionais e, por isso, torna-se alvo dos mecanismos sociais de punição disciplinar para corrigir-lhe o comportamental e evitar a contaminação de outros empregados (MOTTA, 1981).

O silêncio invade até os serviços médicos da empresa. Quando foi encaminhado para o exame periódico de saúde, a médica, ao ver o sobrenome, questiona se havia parentesco com Carlos. Gustavo é encaminhado ao setor de assistência mental, sem receber a mínima explicação sobre os motivos. Esperava apenas uma conversa franca em que pudesse relatar os seus sentimentos e, assim, avaliar a necessidade de algum tipo de apoio psicológico. Não teve sequer o direito ao diálogo. Nenhuma palavra. Recebe apenas a papeleta de encaminhamento. Sente-se desrespeitado. Dirige-se, então, ao setor indicado. A psicóloga que o atende, antes mesmo de ouvi-lo, sugere vinte sessões de terapia. Gustavo se irrita, queria que lhe explicassem os motivos pelos quais deveria submeter-se ao tratamento. Queria apenas ouvir que vivenciara um ato traumático e a terapia poderia ajudá-lo. Apenas isso. Aliás, naqueles últimos tempos, acumulava desrespeito e falta de sensibilidade. Confirmam-se, assim, os achados de Sampaio e Boemer (2000) sobre o despreparo generalizado, inclusive de profissionais da saúde, para lidar com tragédias. Fatos como esses demonstram o quanto considerações humanas ainda estão longe do dia a dia das organizações, apesar de amplamente exploradas, como vantagem estratégica competitiva, as imagens de empregados felizes e as práticas discursivas que exaltam a responsabilidade social (BITTENCOURT; CARRIERI, 2005).

\section{Para concluir}

Este trabalho analisou parte dos fatores que podem ter permeado a decisão do bancário em cometer o suicídio, evidenciando os elementos constitutivos da organização do trabalho que possam ter contribuído para o óbito. Os principais resultados mostraram que o contexto do suicídio decorreu da inter-relação entre o trabalho e a história de vida, sendo que o ritmo pessoal do trabalhador se subordinava integralmente às obrigações profissionais. O vínculo afetivo entre o sujeito e a empresa fora incentivado ao longo de quase três décadas, de forma que os valores organizacionais - como o estímulo ao sucesso desenfrea- 
do, a competição individual, o culto à excelência, o orgulho irrestrito ao trabalho - conduziram-no a desenvolver quadro de sedução e servidão voluntária.

O ego do bancário fora amaciado com doçura, recompensando-se com elogios e promoções o esforço desmesurado. Essas recompensas, entretanto, nunca estavam no mesmo patamar da dedicação, pois lhe era exigido entregar o corpo e a alma ao trabalho, não importasse a hora do dia ou da noite, incluindo os dias não-úteis e até mesmo as férias. À necessidade da organização do trabalho por sujeitos compassivos, soma-se uma característica pessoal do bancário, que era o irrestrito senso de responsabilidade, circunstância ideal para a subjugação aos ditames organizacionais e à exploração de mão de obra.

O trabalho, portanto, faz parte do pano de fundo para compreender-se o processo que conduziu o bancário à ruína familiar, à sumária exasperação psíquica e, em seguida, à ruína profissional. O caso não envolve problemas de assédio à integridade moral, desqualificação, desconfiança ou descrédito, fatores desencadeadores típicos de sofrimento no trabalho, embora haja casos em que, de certa forma, o terror moral se relacione com o suicídio (FINAZZI-SANTOS; SIQUEIRA; MENDES, 2009). Muito pelo contrário, tratava-se de referência quanto ao quesito empregado-padrão. É assim que o processo que resultou no suicídio decorre, em boa parte, de patologia decorrente da devoção do trabalhador à empresa, patologia essa cada vez mais estimulada como símbolo de sucesso do homem moderno e amplamente disseminada pelas revistas de negócios (SIQUEIRA; FREITAS, 2006). O silêncio institucional, por sua vez, relaciona-se com a falta de respeito da corporação para com o empregado no caminho da aposentadoria; relaciona-se com a falta de solidariedade generalizada que tem invadido os ambientes de trabalho. Sua memória foi reduzida a pó: é o silêncio que fala, são palavras não-ditas que acobertam a omissão dos superiores e intimidam os pares a esconder os sentimentos de pesar e consternação.

A empresa se apresenta como grandiosa e símbolo de poder, é o espelho para encontrar-se a felicidade. As novas formas de organização do trabalho disseminam conceitos novos como empregabilidade, individualismo, competição interna, foco no cliente, autogerenciamento e polivalência. A dominação física é substituída por mecanismos de controle psíquicos muito mais eficientes para estimular o empregado a cumprir espontaneamente os imperativos organizacionais. As evidências encontradas levam a questionar a falta de efetividade das políti- cas de recursos humanos em assegurar o bem-estar dos empregados e, o mais importante, revela a face dramática de um sistema social erigido na produção de riquezas a qualquer custo, que subordina completamente considerações humanas a interesses utilitários.

É importante salientar que os acontecimentos post mortem contribuem para reforçar a dissonância entre o discurso organizacional de respeito aos "colaboradores" e a realidade prática a partir do momento em que o irmão do falecido amarga o ostracismo e os antigos colegas de trabalho são desencorajados a manifestar sentimentos de dor perante o trágico acontecimento. É evidente que, quando falamos em suicídio, a decisão de cometê-lo cabe, em última instância, apenas ao sujeito. Cada um tem o seu livre-arbítrio. De qualquer forma, é normal que se procure desvelar os fatores que tenham contribuído para a tragédia. Segundo relato de Gustavo, os burburinhos sussurrados ao pé do ouvido, divulgados por meio de canais informais amplamente eficazes para a divulgação de boatarias, encarregaram-se de conferir tom oficial à notícia: Carlos sucumbira aos problemas conjugais. Explicar o suicídio de um trabalhador como consequência de transtornos mentais ou problemas pessoais pode ser um modo conveniente para acobertar os reais motivos que desencadearam no óbito, atendendo aos interesses da empresa.

Com muita propriedade, Motta (1981) assevera que as organizações se autointitulam acima de qualquer suspeita, terceirizando ao indivíduo a culpa por conflitos ou doenças. Apesar de comumente associados à patologia mental, é razoável supor que há suicídios de trabalhadores em que a exasperação psíquica não é a causa primeira da morte, mas também a consequência de episódios traumáticos inseridos no contexto laboral, com reflexos na vida privada do sujeito, confirmando o estudo de Dejours (2008) sobre o suicídio de uma executiva cuja vida pessoal entrara em colapso - assim como no caso de Carlos - após dificuldades no trabalho. O suicídio é um gesto brutal que materializa algo que se tornou intolerável, representando o abuso nas relações de poder que sujeita a parte mais fraca à subserviência, sob o risco de descarte iminente. O trabalho potencializa a sanidade e o senso de pertencimento social quando viabiliza o espaço público da palavra e da criatividade, o respeito entre os colegas e a valorização das potencialidades do sujeito enquanto condição indispensável para o sucesso do empreendimento, em contraste com ambientes opressores que, infelizmente, têm reduzido pessoas a objetos descartáveis.

\section{Contribuição de autoria}

Finazzi-Santos, M. A.: desenvolveu o delineamento, o levantamento, a análise e a interpretação, a elaboração e a revisão do manuscrito. Siqueira, M. V. S.: contribuiu no delineamento, na elaboração, na revisão do manuscrito e na aprovação da versão final. 


\section{Referências}

AGERBO, E. et al. Suicide and occupation: the impact of socio-economic, demographic and pshychiatric differences. Psychological Medicine, v. 37, n. 8, p. 1131-1140, 2007.

ALMEIDA, L. L.; MERLO, A. R. C. Manda quem pode, obedece quem tem juízo: prazer e sofrimento psíquico em cargos de gerência. Cadernos de Psicologia Social do Trabalho, v. 11, n. 2, p. 139-157, 2008.

ALVAREZ, A. O Deus selvagem: um estudo do suicídio. São Paulo: Companhia das Letras, 1999.

ANTUNES, R. Adeus ao trabalho? Ensaio sobre as metamorfoses e a centralidade do mundo do trabalho. São Paulo: Cortez, 2000.

BARDIN, L. Análise de conteúdo. Lisboa: Edições 70, 1977.

BEDEIAN, A. G. Suicide and occupation: a review. Journal of Vocational Behavior, v. 21, n. 2, p. 206-223, 1982.

BENEVIDES, M. G. Liberdade é escravidão: uma visão orwelliana das histórias e das memórias do processo de transformação institucional do Banco do Brasil (1984-2000). Fortaleza: LCR, 2002.

BERMAN, A. L. Case consultation: suicide in the workplace. Suicide and Life-Threatening Behavior, v. 23, n. 2, p. 268-272, 1993.

BITTENCOURT, E.; CARRIERI, A. Responsabilidade social: ideologia, poder e discurso na lógica empresarial. Revista de Administração de Empresas, v. 45, p. 10-22, 2005. Edição Especial, Minas Gerais. Disponível em: <http://www.16fgv.br/rae/artigos/3475. pdf $>$. Acesso em: 17 dez. 2009.

BLAKELY, T. A.; COLLINGS, S. C. D.; ATKINSON, J. Unemployment and suicide. Evidence for a casual association? Journal of Epidemiology and Community Health, v. 57, n. 8, p. 594-600, 2003.

BOTEGA, N. J. et al. Prevenção do comportamento suicida. Psico-PUCRS, v. 37, n. 3, p. 213-220, 2006.

BRITO, M. J. et al. Gestão de pessoas em análise: disciplina e subjetividade no espaço organizacional. Revista Eletrônica de Gestão Organizacional, v. 4, n. 1, p. 1-14, 2006. Disponível em: <http://www.ufpe.br/ gestoog/index.php/gestão/article/view/147> Acesso em: 25 nov. 2009

CALGARO, J. C. C.; SIQUEIRA, M. V. S. Servidão e solidão: duas faces do gerencialismo contemporâneo. In: MENDES, A. M. (Org.). Trabalho e saúde: o sujeito entre emancipação e servidão. Curitiba: Juruá, 2008. Cap. 8.

CAMUS, A. O mito de sísifo: ensaio sobre o absurdo. Rio de Janeiro: Record, 2004.

CLEMENTS, P. et al. Benefits of community meetings in the corporate settings after the suicide of a coworker. Journal of Psychosocial Nursing and Mental Health Services, v. 41, n. 4, p. 45-49, 2003.

DEJOURS, C. A banalização da injustiça social. Rio de Janeiro: Fundação Getúlio Vargas, 2003.

Novas formas de servidão e de suicídio. In: MENDES, A. M. (Org.). Trabalho e saúde: o sujeito entre emancipação e servidão. Curitiba: Juruá, 2008. Cap. 2.

DEJOURS, C.; BÈGUE, F. Suicídio e trabalho: o que fazer? Brasília: Paralelo 15, 2010.

DRUCK, M. G. Globalização e reestruturação produtiva: o fordismo e/ou japonismo. Revista de Economia Política, v. 19, n. 2, p. 31-48, 1999.

ENRIQUEZ, E. O indivíduo preso na armadilha da estrutura estratégica. Revista de Administração de Empresas, v. 37, n. 1, p. 18-29, 1997a.

. Os desafios éticos nas organizações modernas. Revista de Administração de Empresas, v. 37, n. 2, p. 6-17, 1997b.

FARIA, J. H. (Org.). Análise crítica das teorias e práticas organizacionais. São Paulo: Atlas, 2007.

FERREIRA, M. C. A ergonomia da atividade se interessa pela qualidade de vida no trabalho? Reflexões empíricas e teóricas. Cadernos de Psicologia Social do Trabalho, v. 11, n. 1, p. 83-99, 2008.

FINAZZI-SANTOS, M. A. Patologia da solidão: o suicídio de bancários no contexto da nova organização do trabalho. 2009, 238 f. Dissertação (Mestrado em Administração)-Faculdade de Economia, Administração e Ciências da Informação e Documentação, Universidade de Brasília, Brasília, 2009.

FINAZZI-SANTOS, M. A.; SIQUEIRA, M. V. S.; MENDES, M. E. Tentativas de suicídio de bancários no contexto das reestruturações produtivas. In: ENCONTRO NACIONAL DA ASSOCIAÇÃO NACIONAL DE PÓS-GRADUAÇÃO E PESQUISA EM ADMINISTRAÇÃO, 33., 2009, São Paulo. Anais... São Paulo: ANPAD, 2009. 1 CD-ROM.

FLACH, L. et al. Sofrimento psíquico no trabalho contemporâneo: analisando uma revista de negócios. Psicologia \& Sociedade, v. 21, n. 2, p. 193-202, 2009.

FOUCAULT, M. Vigiar e punir. Petrópolis: Vozes, 1987.

FREITAS, M. E. Cultura organizacional: o doce controle no clube dos raros. In: MOTTA, F. C. P.; CALDAS, M. (Org.). Cultura organizacional e cultura brasileira. São Paulo: Atlas, 1997. Cap. 17.

Cultura organizacional: identidade, sedução e carisma? Rio de Janeiro: Fundação Getúlio Vargas, 1999.

FREITAS, M. E.; HELOANI, R.; BARRETO, M. Assédio moral no trabalho. São Paulo: Cengage, 2008. 
GASKELL, G. Entrevistas individuais e grupais. In: BAUER, M. W.; GASKELL, G. (Org.). Pesquisa qualitativa com texto, imagem e som: um manual prático. Petrópolis: Vozes, 2002. Cap. 3.

GIBBS, J. P. Status integration and suicide: occupational, marital, or both? Social Forces, v. 79, n. 2, p. 363-384, 2000.

GOLDMAN, K. D.; SCHMALZ, K. J. "I gave at the office," but did I give enough? Handling traumatic events. Health Promotion Practice, v. 4, n. 1, p. 5-7, 2003.

GRISCI, C. L. I.; BESSI, V. G. Modos de trabalhar e ser na reestruturação bancária. Sociologias, v. 6, n. 12, p. 160-200, 2004.

GUERREIRO RAMOS, A. A nova ciência das organizações: uma reconceituação da riqueza das nações. Rio de Janeiro: Fundação Getúlio Vargas, 1981.

GUNNELL, D.; LEWIS, G. Studying suicide from the life course perspective: implications for prevention. British Journal of Psychiatry, v. 187, n. 3, p. 206-208, 2005.

HAWTON, K. et al. The psychological autopsy approach to studying suicide: a review of methodological issues. Journal of Affective Disorders, v. 50, n. 2-3, p. 269-76, 1998.

HEIDEGGER, M. Ser e tempo. Petrópolis: Vozes, 2005.

HELOANI, R. Gestão e organização no capitalismo globalizado: história da manipulação psicológica do trabalho. São Paulo: Atlas, 2003.

HIYAMA, T.; YOSHIHARA, M. New occupational threats to Japanese physicians: karoshi (death due to overwork) and karojisatsu (suicide due to overwork). Occupational and Environmental Medicine, v. 65, n. 6, p. 428-429, 2008.

HJELMELAND, H.; KNIZEK, B. L. Why we need qualitative research in suicidology. Suicide and LifeThreatening Behavior, v. 40, n. 1, p. 74-80, 2010.

JINKINGS, N. Trabalho e resistência na "fonte misteriosa": os bancários no mundo da eletrônica e do dinheiro. Campinas: Unicamp, 2002.

KPOSOWA, A. J. Suicide mortality in the United States: differentials by industrial and occupational groups. American Journal of Industrial Medicine, v. 36, n. 6, p. 645-652, 1999.

LANCMAN, S.; SZNELWAR, L. I. (Org.). Christophe Dejours: da psicopatologia à psicodinâmica do trabalho. Rio de Janeiro: Fiocruz, 2008.

LARANJEIRA, S. M. G. Reestruturação produtiva no setor bancário: a realidade dos anos 90. Educação \& Sociedade, v. 18, n. 61, p. 110-138, 1997.

LEITÃO, S. P.; FORTUNATO, G.; FREITAS, A. S. Relacionamentos interpessoais e emoções nas organizações: uma visão biológica. Revista de Administração Pública, v. 40, n. 5, p. 883-907, 2006.
LIPIETZ, A. As relações capital-trabalho no limiar do século XXI. Ensaios FEE, v. 12, n. 1, p. 101-130, 1991.

MACIEL, R. H. et al. Assédio moral no trabalho: impactos sobre a saúde dos bancários e sua relação com gênero e raça. Sindicato dos Bancários de Pernambuco/Contraf, 2006.

MELTZER, H. et. al. Patterns of suicide by occupation in England and Wales: 2001-2005. The British Journal of Psychiatry, v. 193, n. 1, p. 73-76, 2008.

MENDES, A. M. Pesquisa em psicodinâmica: a clínica do trabalho. In: (Org.). Psicodinâmica do trabalho: teoria, métodos e pesquisas. São Paulo: Casa do Psicólogo, 2007. Cap. 3.

MORGAN, G. Paradigms, metaphors, and puzzle solving in organization theory. Administrative Science Quarterly, v. 25, n. 4, p. 605-622, 1980.

MOTA, C. M.; TANURE, B.; NETO, A. C. Estresse e sofrimento no trabalho dos executivos. Psicologia em Revista, v. 14, n. 1, p. 107-130, 2008.

MOTTA, F. C. P. O poder disciplinar nas organizações formais. Revista de Administração de Empresas, v. 21, n. 4, p. 33-41, 1981.

MOTTA, F. C. P.; FREITAS, M. E. (Org.). Vida psíquica e organização. Rio de Janeiro: Fundação Getúlio Vargas, 2000.

NAKAO, M. et al. A 2-year cohort study on the impact of an Employee Assistance Programme (EAP) on depression and suicidal thoughts in the male Japanese workers. International Archives of Occupational and Environmental Health, v. 81, n. 2, p. 151-157, 2007.

NISHIYAMA, H.; JOHNSON, J. V. Karoshi - death from overwork: occupational health consequences of Japanese production management. International Journal of Health Services, v. 27, n. 4, p. 625-641, 1997.

PAGÈS, M. et al. O poder das organizações. São Paulo: Atlas, 1993.

PAIVA, L. A. S. Patologia forense nas mortes com evidente ação do fogo. Saúde, Ética \& Justiça, v. 11, n. 1-2, p. 1-7, 2006.

PAIVA JÚNIOR, F. G.; MELLO, S. C. B. Pesquisa qualitativa nos estudos organizacionais: contribuições fenomenológicas de Alfred Schütz. Organizações em Contexto, v. 4, n. 8, p. 24-48, 2008.

PAULA, A. P. P. Tragtenberg revisitado: as inexoráveis harmonias administrativas e a burocracia flexível. Revista de Administração Pública, v. 36, n. 1, p. 127144, 2002.

PRETI, A.; MIOTTO, P. Social economic influence on suicide: a study of situation in Italy. Archives of Suicide Research, v. 5, n. 2, p. 141-156, 1999.

PRIETO, D.; TAVARES, M. Fatores de risco para suicídio e tentativa de suicídio: incidência, eventos estressores e transtornos mentais. Jornal Brasileiro de Psiquiatria, v. 54, n. 2, p. 146-154, 2005. 
RAY, M. The richness of phenomenology: philosophic, theoretic and methodologic concernes. In: MORSE, J. M. (Ed.). Critical issues in qualitative research methods. Thousand Oaks: Sage Publications, 1994. Cap. 7.

RODRIGUES, L. C. Metáforas do Brasil: demissões voluntárias, crises e rupturas no Banco do Brasil. São Paulo: Annablume, 2004.

ROSSI, E. Z. Reabilitação e reinserção no trabalho de bancários portadores de LER/DORT: análise psicodinâmica. 2008, 267 f. Tese (Doutorado em Psicologia Social do Trabalho e das Organizações)Instituto de Psicologia, Universidade de Brasília, Brasília, DF, 2008.

SAMPAIO, M. A.; BOEMER, M. R. Suicídio - um ensaio em busca de um desvelamento do tema. Revista da Escola de Enfermagem da USP, v. 34, n. 4, p. 325331, 2000.

SARAIVA, L. A. S.; IRIGARAY, H. A. R. Políticas de diversidade nas organizações: uma questão de discurso? Revista de Administração de Empresas, v. 49, n. 3, p. 337-348, 2009.

SCHMIDTKE, A. et al. Suicide rates in the world: Update. Archives of Suicide Research, v. 5, n. 1, p. 8189, 1999.

SEGNINI, L. R. P. Reestruturação nos bancos do Brasil: desemprego, subcontratação e intensificação do trabalho. Educação \& Sociedade, v. 20, n. 67, p. 185-211, 1999.

SELIGMANN-SILVA, E. Desgaste mental no trabalho dominado. Rio de Janeiro: Cortez, 1994.
SHIELDS, M. Long working hours and health. Health Reports, v. 11, n. 2, p. 33-48, 1999.

SIQUEIRA, M. V. S. Gestão de pessoas e discurso organizacional. Goiânia: Editora UCG, 2006.

SIQUEIRA, M. V. S.; FREITAS, M. E. O papel da mídia especializada em negócios na reprodução do discurso organizacional em recursos humanos no Brasil. In: ENCONTRO NACIONAL DA ASSOCIAÇÃO NACIONAL DE PÓS-GRADUAÇÃO E PESQUISA EM ADMINISTRAÇÃO, 30., 2006, Salvador. Anais... Salvador: ANPAD, 2006. 1 CD-ROM.

STACK, S. Occupation and suicide. Social Science Quartely, v. 82, n. 2, p. 384-396, 2001.

STRAUSS, A.; CORBIN, J. Pesquisa qualitativa: técnicas e procedimentos para o desenvolvimento de teoria fundamentada. Porto Alegre: Artmed, 2008.

TAYLOR, P. Age, labour market condition and male suicide rates in selected countries. Ageing and Society, v. 23, n. 1, p. 25-40, 2003.

TRAGTENBERG, M. Burocracia e ideologia. São Paulo: Ática, 1985.

WILHELM, K. et al. Work and mental health. Social Psychiatric \& Epidemiology, v. 39, n. 11, p. 866-873, 2004.

XAVIER, E. P. Um minuto de silêncio: réquiem aos bancários mortos no trabalho. Porto Alegre: Sindicato dos Bancários de Porto Alegre, 1998. 